\title{
Léxico e história social: um estudo da variante lexical neve no Atlas Linguístico da Mesorregião Sudeste de Mato Grosso
}

\author{
Marigilda Antônio CUBA * \\ Aparecida Negri ISQUERDO **
}

Resumo: Este texto analisa marcas de influências interculturais e linguísticas no vocabulário, com base na produtividade da variante neve como designação de "orvalho" e "cerração", registrada no Atlas Linguístico da mesorregião Sudeste de Mato Grosso. Os dados foram comparados com os de cinco atlas linguísticos brasileiros das regiões Nordeste, Sudeste e Sul do Brasil, com vistas a analisar a questão da manutenção e/ou disseminação do uso dessa variante, segundo a história social da região investigada, cujo povoamento foi decorrente de diversos fluxos migratórios.

Palavras-chave: Atlas linguístico; Léxico; Contatos linguísticos; Contatos interétnicos.

Abstract: This text analyses brand of intercultural and linguistic
influences on the vocabulary, based on variant snow (neve)
productivity to nominate dew (orvalho), registered on Mato Grosso
Southeast Area Linguistic Atlas (Atlas Linguístico da mesorregião

* Mestrado em Estudos de Linguagens, pela UFMS, em 2009. Professora da Universidade Federal de Mato Grosso - Campus de Cuiabá. Contato: cubamac@terra.com.br.

** Doutorado em Letras (Linguística e Língua Portuguesa), pela Universidade Estadual Paulista Júlio de Mesquita Filho, UNESP, em 1996. Docente aposentada pela Universidade Federal de Mato Grosso do Sul, onde atualmente é Professora Visitante. Contato: anegri.isquerdo@terra.com.br. 
Sudeste de Mato Grosso). The data were compared with five Brazilian linguistic atlas, concerned the regions Northeast, Southeast and South, to analyze the persistence and/or the dissemination in this variant usage, according the investigated region social history, whose settlement was resulting from several migratory flows.

Keywords: Linguistic atlas; Lexicon; Linguistic contacts; Interethnic contacts.

\section{Apresentação}

Os fatores que ocasionam as variações linguísticas estão intrinsecamente relacionados e submetidos a uma rede de circunstâncias internas e externas à língua. Alguns desses fatores podem ser traduzidos na relação entre língua e espaço físico; são as variações geográficas que, por sua vez, estão constantemente condicionadas a fatores sociais, culturais e históricos.

O homem, ao migrar de um local a outro, transporta consigo seus conhecimentos e sua linguagem. Interagindo com indivíduos de culturas diferentes, os integrantes de uma comunidade externam sua concepção de mundo e, concomitantemente, assumem as características pertencentes a outros grupos e a outras culturas. Partindo, pois, da premissa que o Estado de Mato Grosso recebeu migrantes de várias regiões brasileiras, que trouxeram consigo a variante da língua portuguesa falada em seus locais de origem, este artigo tem como objetivo identificar e descrever marcas de influências interculturais e linguísticas na fala dos habitantes da Mesorregião Sudeste de Mato Grosso, decorrentes do contato entre povos de diferentes regiões brasileiras que ali se fixaram em dois momentos diferentes de sua história, com base em dados geolinguísticos.

Um atlas linguístico, segundo Aguilera (1998, p. 12), configura-se como um conjunto de mapas em que se registram os traços fonéticos, lexicais e/ou morfossintáticos característicos de uma língua num determinado âmbito geográfico. Em outras 
palavras, é um repositório de diferentes realizações que constituem as diversas normas que coexistem num sistema linguístico e que configuram seus dialetos e/ou falares. Isquerdo (2007, p. 533), por sua vez, pondera que uma das contribuições de um atlas linguístico é resgatar e registrar particularidades étnicas e históricoculturais por meio da distribuição espacial de formas linguísticas. Nessa perspectiva, os fatos linguísticos registrados num atlas tornam-se fotografias da fala de um grupo social. As cartas linguísticas que mapeiam o nível lexical da língua, por exemplo, fornecem dados concretos e significativos sobre o uso e a disseminação espacial de unidades lexicais, razão por que fornecem parâmetros para o estudo dos regionalismos (norma lexical característica de determinada área geográfica).

Este artigo centra-se na discussão do uso da unidade lexical neve na nomeação dos conceitos "as gotinhas de água que molham a grama pela manhã e à noite" (orvalho) e a "espécie de fumaça que cobre tudo de manhã" (neblina), tomando como ponto de partida os dados registrados nas cartas léxicas 12 e 13 do Atlas Linguístico da Mesorregião Sudeste de Mato Grosso ALMESEMT (CUBA, 2009). ${ }^{1}$ Dado o interesse de abordar o componente interétnico, foi verificada a questão da presença dessa mesma variante para nomear esses mesmos conceitos em atlas linguísticos já publicados de estados brasileiros: Carta 13 - librina - do Atlas Prévio dos Falares Baianos - APFB (ROSSI, 1963); Carta 4 - orvalbo - do Esboco do Atlas Lingüístico de Minas Gerais - EALMG (RIBEIRO; ZÁGARI, 1977); Cartas 019 - garoa; 24 - cerração - e 26 - orvalbo - do Atlas Linguiistico da Paraíba - ALPB (ARAGÃO; MENEZES, 1984); Cartas 32 - orvalbo - e 33 - cerração - do Atlas

\footnotetext{
${ }^{1} \mathrm{O}$ Atlas Linguístico da Mesorregião Sudeste de Mato Grosso (ALMESEMT) é produto da Dissertação de Mestrado defendida por Marigilda Antonio Cuba no Programa de Pós-graduação em Estudos de Linguagens, da Universidade Federal de Mato Grosso do Sul, em março de 2009, trabalho orientado pela Prof. ${ }^{a}$ Dr. ${ }^{a}$ Aparecida Negri Isquerdo.
} 
Lingüistico do Paraná - ALPR (AGUILERA, 1994) e as cartas 0032.a - nevoeiro/cerração/ neblina - e 0050.a - orvalho - do Atlas Lingüistico do Mato Grosso do Sul-ALMS (OLIVEIRA, 2007).

A escolha dessa variante em detrimento de outras do ALSEMEMT pautou-se no fato de o seu uso evidenciar tendências de influências linguísticas das diferentes levas de migrantes que contribuíram para o povoamento da região e na hipótese de um provável continuum linguístico existente entre os Estados de Mato Grosso e de Mato Grosso do Sul, apesar da divisão políticoadministrativa ocorrida em 1979. No caso, a presença da variante neve denuncia a influência linguística deixada pela primeira leva de migrantes, os nordestinos, vinda para a área investigada no final do século XIX e início do século XX.

\section{0 processo de povoamento da Mesorregião Sudeste de Mato} Grosso

Alguns aspectos geográficos e uma breve descrição histórica da região investigada se impõem para que se possa, com maior precisão, compreender as questões discutidas neste trabalho. Desde meados de 1700 , o vínculo capitalista que impulsiona a migração está presente no processo de desenvolvimento de Mato Grosso. Em 1736, com a abertura da estrada Goiás-Cuiabá, começaram a ser definidos os núcleos mineradores no Estado: Cuiabá, Vila Bela da Santíssima Trindade, Diamantino e Rosário Oeste.

Já a ocupação da Mesorregião Sudeste mato-grossense aconteceu em três períodos distintos. Primeiramente, no século XIX, motivada pela atividade mineradora; num segundo momento, no século XX, impulsionada pela agricultura e pecuária nacional; e, no início do século XXI, a região experimenta um terceiro e novo período na história, o da industrialização, período em que a expansão populacional atrai habitantes da própria região ou da capital, Cuiabá.

A mineração de diamantes foi a base da economia dessa região no século XIX, atraindo garimpeiros pela grande quantidade de ouro e diamante encontrada próximos aos rios Garças e 
Araguaia. Por volta de 1890-1920, a Mesorregião Sudeste matogrossense recebeu levas de migrantes baianos, cearenses, goianos, maranhenses e mineiros que, perto dos rios Cassununga e Garças, foram iniciando núcleos de povoamento que acabaram dando origem às atuais cidades de Alto Araguaia, de Dom Aquino, de Guiratinga, de Poxoreo e de Tesouro.

A partir dos anos 70 , do século $\mathrm{XX}$, com a redução da garimpagem de diamantes, essa mesorregião passou a ter destaque na economia regional com a produção de grãos e de cana-de-açúcar, com a criação de gado de corte e de leite e, mais recentemente, com a produção de algodão. Nesse período, a política de integração do Centro-Oeste trouxe uma valorização dos solos regionais, não somente pela sua fertilidade natural, mas também como reserva de valor. A consequência dessa valorização das terras atraiu novas levas de migrantes, sobretudo de sulistas (gaúchos, catarinenses e paranaenses), que se fixaram na região para atuarem, sobretudo, na agropecuária.

Atualmente, a Mesorregião Sudeste mato-grossense é uma das principais geradoras de emprego do Estado, especialmente Rondonópolis, principal núcleo urbano da região, em função de sua posição estratégica em relação a Goiás, ao Sudeste do Brasil, ao Mato Grosso do Sul e ao próprio Estado de Mato Grosso. As transformações infraestruturais, econômicas e sociais, geradas pelo processo de industrialização pelo qual vem passando, têm ocasionado um novo impulso no desenvolvimento populacional dessa área geográfica. Profissionais de várias áreas do conhecimento e vindos de diversas regiões do Brasil têm se instalado ali, à procura de novas oportunidades. O convívio entre a população proveniente das regiões Nordeste, Sudeste e Sul do Brasil com o povo matogrossense contribuiu para a configuração de uma sociedade com características linguístico-culturais distintas, que se refletem na variante do português falada nessa região, como demonstram os dados mapeados pelo Atlas Linguístico da Mesorregião Sudeste de Mato Grosso.

O Quadro 1, a seguir, reúne informação acerca do exposto, explicitando, além da identificação do município que integra a rede 
de pontos do ALMESEMT e respectiva microrregião em que está inserido, os anos relativos à fixação dos primeiros habitantes na localidade e à municipalização do povoado. Por fim, informa as levas migratórias que aportaram em cada município em duas fases do povoamento: 1880 a 1940 e 1950 a 2000 que, respectivamente, se referem ao primeiro e ao segundo período de expansão populacional.

\begin{tabular}{|c|c|c|c|c|c|}
\hline \multicolumn{6}{|c|}{ Povoamento da Mesorregião Sudeste de Mato Grosso } \\
\hline Município & Microrregião & $\begin{array}{c}\text { Primeiros } \\
\text { hab. }\end{array}$ & $\begin{array}{c}\text { Municipa- } \\
\text { lização }\end{array}$ & \multicolumn{2}{|c|}{ Povoamento } \\
\hline & $\begin{array}{c}\text { Primeiro } \\
\text { momento } \\
(1880-1940)\end{array}$ & $\begin{array}{c}\text { Segundo } \\
\text { momento } \\
(1950-2000)\end{array}$ \\
\hline Campo Verde & $\begin{array}{l}\text { Primavera do } \\
\text { Leste }\end{array}$ & 1886 & 1988 & $\begin{array}{c}\text { mineiros, } \\
\text { goianos e } \\
\text { mato- } \\
\text { grossenses }\end{array}$ & $\begin{array}{l}\text { paranaenses e } \\
\text { gaúchos }\end{array}$ \\
\hline Dom Aquino & Rondonópolis & 1920 & 1958 & $\begin{array}{l}\text { poxorenses, } \\
\text { cearenses, } \\
\text { baianos e } \\
\text { maranhense } \\
\text { s }\end{array}$ & $\begin{array}{l}\text { gaúchos e } \\
\text { mato- } \\
\text { grossenses }\end{array}$ \\
\hline Tesouro & Tesouro & 1897. & 1953 & $\begin{array}{c}\text { baianos, } \\
\text { maranhense } \\
\text { s e } \\
\text { cearenses }\end{array}$ & $\begin{array}{c}\text { nordestinos, } \\
\text { gaúchos e } \\
\text { mato- } \\
\text { grossenses }\end{array}$ \\
\hline Poxoreo & Tesouro & 1919 & 1938 & $\begin{array}{c}\text { mineiros, } \\
\text { baianos e } \\
\text { maranhense } \\
\mathrm{s}\end{array}$ & gaúchos \\
\hline Guiratinga & Tesouro & 1890 & 1943 & $\begin{array}{l}\text { goianos, } \\
\text { baianos e } \\
\text { mineiros }\end{array}$ & $\begin{array}{c}\text { paranaenses, } \\
\text { paulistas e } \\
\text { gaúchos }\end{array}$ \\
\hline Rondonópolis & Rondonópolis & 1902 & 1953 & $\begin{array}{c}\text { Goianos e } \\
\text { mato- } \\
\text { grossesnses }\end{array}$ & $\begin{array}{l}\text { gaúchos, } \\
\text { paranaenses e } \\
\text { paulistas }\end{array}$ \\
\hline Itiquira & Rondonópolis & 1904 & 1958 & $\begin{array}{l}\text { paulistas, } \\
\text { mineiros, } \\
\text { gaúchos e } \\
\text { paranaenses }\end{array}$ & $\begin{array}{c}\text { gaúchos, } \\
\text { paranaenses e } \\
\text { paulistas }\end{array}$ \\
\hline Alto Araguaia & Alto Araguaia & 1920 & 1921 & baianos & $\begin{array}{l}\text { baianos, } \\
\text { gaúchos e } \\
\text { goianos }\end{array}$ \\
\hline
\end{tabular}

Quadro 1 - Processo de povoamento da área investigada 


\section{O ALMESEMT: contextualização}

O Atlas Linguístico da Mesorregião Sudeste de Mato Grosso fundamentou-se nos pressupostos teórico-metodológicos que embasam as pesquisas dialetológicas atuais, que, em sua grande maioria, são orientadas pelos parâmetros da Dialetologia Pluridimensional, a qual, conforme Thun (1998, p. 369), se "caracteriza pelo alargamento do seu campo de observação e por um trabalho em profundidade mais desenvolvido".

A pluridimensionalidade de um atlas está representada no caráter metodológico no qual ele se insere. Os primeiros atlas linguísticos tinham uma dimensão estritamente diatópica, o que lhes conferia o status de monodimensionais, ou seja, os informantes se restringiam a homens adultos, rurícolas, analfabetos e sedentários - o HARAS, como os identifica Zágari (1998, p. 35). Já contemporaneamente, busca-se, numa pesquisa dialetológica, analisar os diversos fatores - social, etário, sexual, dentre outros que influenciam no uso da língua por uma comunidade de falantes. No Brasil, Thun (1998, p. 375) aponta o Atlas Linguístico de Sergipe (1987) e o Atlas Linguístico do Paraná (1994) como os trabalhos que trazem as primeiras manifestações pluridimensionais em um atlas linguístico brasileiro. Segundo o autor, esses dois atlas se configuram como bidimensionais, pois incluem a variação diagenérica (ambos entrevistaram um homem e uma mulher em cada ponto da rede).

O Atlas Linguístico da Mesorregião Sudeste de Mato Grosso, por sua vez, seguindo essa tendência metodológica, considerou as seguintes dimensões ao definir a metodologia de coleta de dados: diatópica (rede de 08 pontos), diageracional (informantes de duas faixas etárias) e diassexual (dois sexos). Além disso, foram consideradas as variáveis escolaridade e naturalidade.

Em termos diatópicos, na definição da rede de pontos do atlas, foram selecionadas 08 localidades que cobriram as quatro microrregiões que integram a Mesorregião selecionada para a 
pesquisa: ${ }^{2}$ Alto Araguaia, Campo Verde, Dom Aquino, Guiratinga, Itiquira, Poxoreo, Rondonópolis e Tesouro. Para a seleção dessas localidades foram considerados os seguintes critérios: i) a natureza do povoamento; ii) a proposta de Nascentes (1958, p. 53) que, em suas Bases para a Elaboração do Atlas Lingüistico do Brasil, elencou 23 pontos de inquéritos para cobrir a área do então Estado de Mato Grosso; iii) a antiguidade; iv) os aspectos histórico-culturais; v) a densidade demográfica; vi) a distribuição geográfica; vii) a área de fronteira entre a Mesorregião Sudeste mato-grossense e outros Estados; e, viii) a representatividade de localidades das quatro microrregiões que formam a Mesorregião Sudeste.

Já em termos de variáveis de cunho sociolinguístico, foram inquiridos informantes masculinos e femininos, de duas faixas etárias - 18 a 30 e 45 a 70 anos -, com escolaridade até a $8^{\text {a }}$ série do Ensino Fundamental, nascidos no local, ou lá residentes por mais de $50 \%$ da idade, no caso dos informantes da segunda faixa etária. ${ }^{3}$ Obedecendo, pois, a esse perfil foram entrevistadas 4 pessoas por localidade, perfazendo um total de 32 informantes.

\footnotetext{
${ }^{2}$ A Mesorregião Sudeste de Mato Grosso é composta de 04 microrregiões que abrigam 22 municípios: Alto Araguaia (Alto Araguaia, Alto Garças e Alto Taquari); Primavera do Leste (Campo Verde e Primavera do Leste); Rondonópolis (Dom Aquino, Itiquira, Jaciara, Juscimeira, Pedra Preta, Rondonópolis, São José do Povo e São Pedro da Cipa) e Tesouro (Araguainha, General Carneiro, Guiratinga, Pontal do Araguaia, Ponte Branca, Poxoreo, Ribeirãozinho, Tesouro e Torixoréu).

${ }^{3}$ Essa exceção acabou aplicando-se apenas à informante da segunda faixa etária de Campo Verde, em decorrência da dificuldade de localizar informantes acima de 45 anos ali nascidos. Embora essa localidade se configure como um núcleo populacional antigo (1886), tem data de emancipação recente (1988) e tem recebido muitos migrantes de outros Estados, conforme Quadro I, o que dificulta a localização de grande contingente de habitantes nascidos no local. Além disso, é preciso considerar o conjunto de características estabelecidas no perfil dos informantes (às vezes eram localizadas informantes que atendiam o critério naturalidade, mas não preenchiam os quesitos escolaridade $\mathrm{e}$ idade, por exemplo).
} 
As entrevistas foram realizadas in loco, com o auxílio de um Questionário Linguístico, ${ }^{4}$ contendo 318 questões, distribuídas em 2 questionários: o fonético-fonológico, com 161 perguntas, e o semântico-lexical, com 157 questões, além de 4 temas para discursos semidirigidos e 6 perguntas metalinguísticas.

O ALMESEMT contém 122 cartas fonéticas e 121 lexicais, além de três cartas introdutórias. Os dados mapeados nas 243 cartas linguísticas apontam algumas tendências na fala dos habitantes da região investigada, dentre as quais a manifestação de marcas de influências interculturais e linguísticas na fala dos habitantes dos municípios estudados, decorrentes do contato entre povos de diferentes regiões brasileiras que ali se fixaram. Este trabalho centrase no exame de uma variante lexical - neve -, cujo uso evidencia a influência de aspectos da história social da região no vocabulário dos seus habitantes.

\section{A distribuição diatópica da variante neve: o que dizem o ALMESEMT e os atlas regionais brasileiros publicados}

A variante neve foi mapeada como designação de dois conceitos distintos no ALMESEMT: na carta 12, com 3,13\% de produtividade, e na carta 13 , com $18,75 \%$ de ocorrências.

O conceito o que molha a grama de manhã, vinculada à área semântica fenômenos atmosféricos, no ALMESEMT, deu origem à carta léxica 12 , originada da pergunta 12 do questionário semânticolexical (de manhã bem cedo, a grama geralmente está molhada. Como chamam aquilo que molha a grama?). Como demonstra a

${ }^{4}$ O ALMESEMT adotou o Questionário Linguístico do Projeto Atlas Linguístico do Brasil (Projeto ALiB), de 2001, praticamente na íntegra, apenas suprimindo 107 perguntas do questionário semântico-lexical e acrescentando 65 perguntas extraídas do Questionário Linguístico do Atlas Linguístico de Mato Grosso do Sul, com o objetivo de apurar dados que possam retratar com maior fidelidade a realidade linguística da área pesquisada. 
Figura 1, essa carta registra as seguintes variantes: sereno - 59,38\%; orvalho - $25 \%$; neblina - $12 \%$, e neve - 3,13\% (ocorrência única).

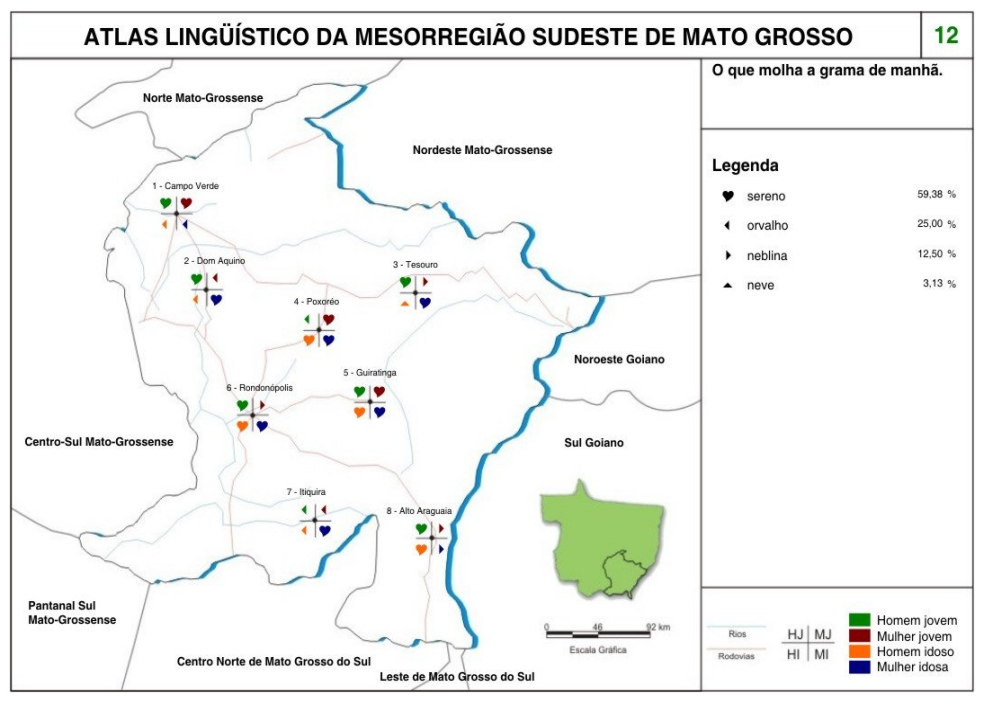

Figura 1 - Carta léxica 12 do Atlas Linguístico da Mesorregião Sudeste de Mato Grosso

O Quadro 2, a seguir, apresenta o conjunto de variantes extraídas dos atlas linguísticos brasileiros que contêm cartas relativas ao conceito as gotinhas de água que molham a grama pela manhã e à noite (orvalho), considerando-se, para tanto, as 4 mais produtivas em cada atlas linguístico consultado.

No ALMS, a variante neve teve ocorrência única, ao lado de pingo d'água, geada, dentre outras, e aparece na fala da informante feminina jovem natural de Bataguassu, divisa com o Estado de São Paulo. No ALMESEMT também teve ocorrência única em Tesouro, fornecida pelo informante masculino da segunda faixa etária, filho de baianos. 


\begin{tabular}{|c|c|c|c|c|}
\hline Atlas/carta & $\begin{array}{c}\text { Variante/ } \\
1^{\circ} \text { lugar de } \\
\text { ocorrência }\end{array}$ & $\begin{array}{c}\text { Variante/ } \\
2^{\circ} \text { lugar de } \\
\text { ocorrência }\end{array}$ & $\begin{array}{l}\text { Variante/ } \\
3^{\circ} \text { lugar de } \\
\text { ocorrência }\end{array}$ & $\begin{array}{l}\text { Variante/ } \\
4^{\circ} \text { lugar de } \\
\text { ocorrência }\end{array}$ \\
\hline $\begin{array}{l}\text { EALMG - orvalho } \\
\text { (carta 04) }\end{array}$ & sereno & orvalho & garoa & neve \\
\hline $\begin{array}{l}\text { ALPB - orvalho } \\
\text { (carta 26) }\end{array}$ & sereno & orvalho & neve & chuvinha \\
\hline $\begin{array}{l}\text { ALPR - orvalho } \\
\text { (carta 32) }\end{array}$ & orvalho & sereno & goteira & cerração \\
\hline $\begin{array}{l}\text { ALMS - orvalho } \\
\text { (carta 50. a) }\end{array}$ & sereno & orvalho & garoa & neve \\
\hline $\begin{array}{l}\text { ALMESEMT - orvalho } \\
\text { (carta 12) }\end{array}$ & sereno & orvalho & neblina & neve \\
\hline
\end{tabular}

Quadro 2 - Distribuição das variantes que designam as gotinhas de água que molbam a grama pela manhã e à noite, nos atlas brasileiros publicados

Nota-se, pelos dados do Quadro 2, que a variante neve, na acepção de "orvalho", está em via de desaparecimento, mesmo na fala dos nordestinos e mineiros. Na região Sudeste, ocupa o quarto lugar de ocorrência no Esboço de um Atlas Lingüístico de Minas Gerais (RIBEIRO; ZÁGARI; PASSINI, 1977), tendo sido documentada nas regiões Norte e Oeste de Minas Gerais; na região Nordeste, atingiu o terceiro lugar no Atlas Linguistico da Paraíba (ARAGÃO; MENEZES, 1984a), registrada no leste do Estado, próximo ao litoral, uma ocorrência no Centro-Norte e outra a Oeste. Não foi registrada na região Sul, no Atlas Lingǘstico do Paraná (AGUILERA, 1994), enquanto, no Centro-Oeste, teve ocorrência única, alçando o quarto lugar de ocorrência no Atlas Lingüístico de Mato Grosso do Sul (OLIVEIRA, 2007) e no Atlas Linguístico da Mesorregião Sudeste de Mato Grosso (CUBA, 2009).

Já o conceito fumaça que cobre tudo de manhã, também pertencente à área semântica fenômenos atmosféricos, gerou a carta 13 do ALMESEMT, originada da pergunta 13 do Questionário semântico-lexical usado como instrumento de coleta de dados do projeto (muitas vezes, principalmente de manhã cedo, quase não se pode enxergar por causa de uma coisa parecida com fumaça, que cobre tudo. Como chamam isso?). A Figura 2, na sequência, registra as seguintes variantes documentadas na Mesorregião Sudeste de Mato Grosso: neblina- 
$53,13 \%$; neve - 18,75\%; cerração - 12,5\%; sereno- $6 \%$, além de garoa, fumaçado e nevoado, cada uma com 3,13\% de ocorrência.

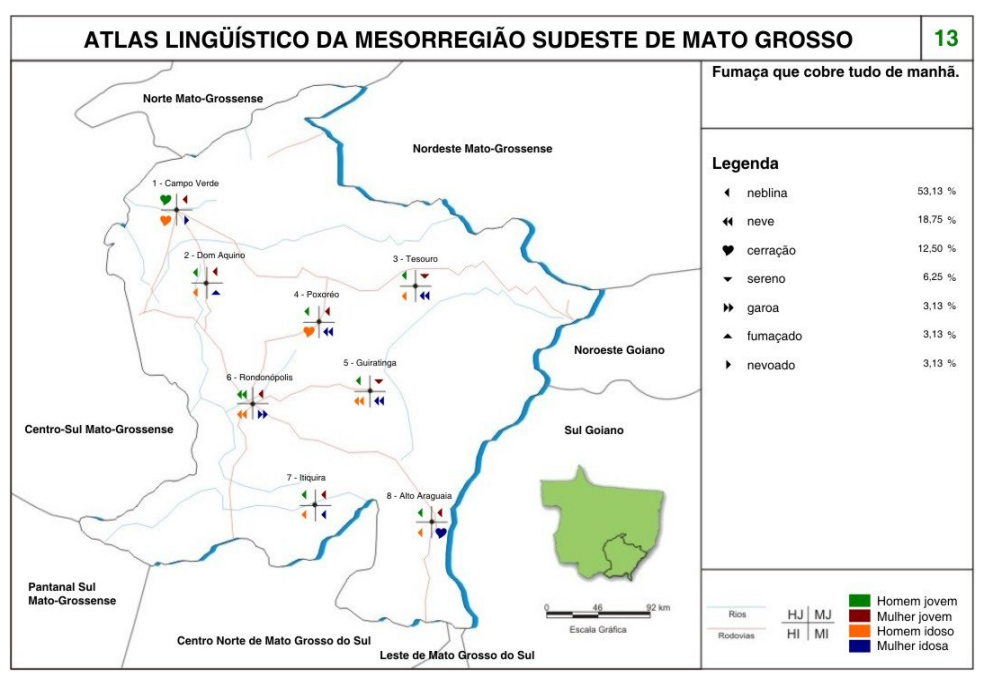

Figura 2 - Carta léxica 13 do Atlas Linguístico da Mesorregião Sudeste de Mato Grosso

Nota-se que a variante neve foi mencionada em quatro localidades, por informantes da segunda faixa etária, exceto em Rondonópolis, que foi registrada na fala do homem jovem, que tem os pais nascidos na mesma localidade. Em Tesouro, a variante foi citada pela informante idosa, divorciada, cujos pais e marido vieram de São Luis do Maranhão. Em Poxoreo, neve surgiu na fala da informante idosa, solteira, que vive com os pais naturais da localidade. Em Guiratinga, foi documentada na fala do homem e da mulher da segunda faixa etária; o homem é filho de guiratinguenses, casado com uma filha de baianos, enquanto a mulher é filha de baiano e goiana, casada com um guiratinguense. Por fim, em Rondonópolis, além do informante jovem, já citado, registrou-se neve na fala do informante idoso, viúvo de uma 
rondonopolitana e filho de mato-grossenses. Também está documentada essa acepção no APFB, no EALMG, no ALPB e no ALMS, como permite visualizar o Quadro 3 que, também contém as quatro variantes mais produtivas nos atlas consultados.

\begin{tabular}{|l|c|c|c|c||}
\hline \multicolumn{1}{|c|}{ Atlas/carta } & $\begin{array}{c}\text { Variante/ } \\
1^{\circ} \text { lugar de } \\
\text { ocorrência }\end{array}$ & $\begin{array}{c}\text { Variante/ } \\
2^{\circ} \text { lugar de } \\
\text { ocorrência }\end{array}$ & $\begin{array}{c}\text { Variante/ } \\
3^{\circ} \text { lugar de } \\
\text { ocorrência }\end{array}$ & $\begin{array}{c}\text { Variante/ } \\
4^{\circ} \text { lugar de } \\
\text { ocorrência }\end{array}$ \\
\hline $\begin{array}{l}\text { APFB - nevoeiro } \\
\text { (carta 13) }\end{array}$ & neve & librina & neblina & nivoada \\
\hline $\begin{array}{l}\text { ALPB - cerração } \\
\text { (carta 24) }\end{array}$ & nevoeiro & neve & sereno & as neves \\
\hline $\begin{array}{l}\text { ALPR - cerração } \\
\text { (carta 33) }\end{array}$ & cerração & neblina & fumaça & garoa \\
\hline $\begin{array}{l}\text { ALMS - } \\
\text { carta 32.a }\end{array}$ & neblina & cerração & nevoeiro & $\begin{array}{l}\text { neve/neve } \\
\text { branquinha }\end{array}$ \\
\hline $\begin{array}{l}\text { ALMESEMT - } \\
\text { carta 13 }\end{array}$ & neblina & neve & cerração & sereno \\
\hline
\end{tabular}

Quadro 3 - Distribuição das variantes que designam a fumaça que cobre tudo de manhã, nos atlas brasileiros publicados

No Atlas Prévio dos Falares Baianos (ROSSI, 1963), a variante neve está presente nas fronteiras com os seguintes Estados: Piauí, Tocantins, Goiás e Minas Gerais. Já no Atlas Lingüístico da Paraíba (ARAGÃO; MENEZES, 1984a), aparece nas fronteiras com os Estados do Rio Grande do Norte, Ceará e Pernambuco, enquanto no Esboço de um Atlas Lingüistico de Minas Gerais (RIBEIRO; ZÁGARI; PASSINI, 1977), neve está registrada a oeste do Estado, nas fronteiras com Goiás, Mato Grosso do Sul e São Paulo. O Atlas Lingüístico do Mato Grosso do Sul (OLIVEIRA, 2007), por sua vez, tem a variante neve mapeada em localidades situadas no centro do Estado de Mato Grosso do Sul. Por fim, no Atlas Lingüístico do Paraná (AGUILERA, 1994), não há registro da variante neve como forma de nomeação do conceito em foco.

Ao contrário do observado no uso da variante neve como parassinônima de orvalho, a produtividade registrada como designação de "neblina/cerração" evidencia maior vitalidade da 
unidade lexical neve, haja vista que ocupa o primeiro lugar de ocorrência no Atlas Prévio dos Falares Baianos (ROSSI, 1963), o segundo lugar no Atlas Lingüistico da Paraíba (ARAGÃO; MENEZES, 1984a) e no Atlas Linguístico da Mesorregião Sudeste de Mato Grosso (CUBA, 2009). Já no Atlas Lingüistico de Mato Grosso do Sul (OLIVEIRA, 2007) atingiu o quarto lugar, não sendo registrado no Atlas Lingüístico do Paraná (AGUILERA, 1994).

A ausência da variante neve no ALPR (AGUILERA, 1994), para designar os conceitos em pauta parece justificável pela própria natureza do povoamento do Estado do Paraná, que recebeu migrantes, em sua maioria, vindos do Sul e do Sudeste do Brasil. Ademais, os habitantes dos Estados do Sul do País (Paraná, Santa Catarina e Rio Grande do Sul) estão habituados com o inverno rigoroso, com frequentes neves em algumas localidades da região. Além disso, uma população habituada com invernos intensos consegue identificar com mais clareza os fenômenos atmosféricos normalmente designados de "orvalho/sereno" e de "neblina/ cerração" e, consequentemente, nomeá-los com os termos específicos. Portanto, para essa população, a unidade neve é usada somente na sua acepção original.

\section{A unidade lexical neve: o que dizem os dicionários}

A unidade lexical neve é definida, por Ferreira (2000), como "precipitação de cristais de gelo, em geral de forma hexagonal e intricadamente ramificados, aglomerados em flocos, formados diretamente pelo congelamento do vapor de água que se encontra em suspensão no ar atmosférico". Já o uso de neve nas regiões Nordeste, Sudeste e Centro-Oeste, para designar os referentes normalmente nomeados de "orvalho/sereno" e "neblina/ cerração" pode decorrer da associação entre características dos referentes em causa. Em virtude da falta de convívio da população dessas regiões com o fenômeno atmosférico "neve", a fumaça "esbranquiçada" que caracteriza o outro fenômeno, a "neblina/ cerração", tem a conotação de "neve", daí o uso dessa variante lexical para designar esse referente. Da mesma forma, a associação 
com "orvalho/sereno" pode estar relacionada à condensação da água já que, na norma padrão, essas unidades lexicais designam a "umidade da atmosfera, que se condensa (principalmente durante a noite) e se deposita, em forma de gotículas, sobre qualquer superfície fria; relento, rocio" (FERREIRA, 2000).

A etimologia dessas unidades lexicais corrobora o exposto: neve: do latim n-ve-, «neve; fig., brancura» (MACHADO, 1987); orvalho, segundo Machado (1987) e Cunha (1996), tem etimologia obscura. Já sereno provém do "lat. serìnu-, «sereno, puro, sem nuvens»" (MACHADO, 1987), enquanto neblina deriva do "cast. neblina, deriv. do lat. nibmla -ae" e cerração, "do lat. tard. serâre (<sera p' ferrolho'), conforme Cunha (1996). Moraes Silva (1813), por seu turno, assim define essas unidades lexicais: neve: "vapor, que, congelando-se na atmosfera, torna a cair em flocos mui alvos [...]; a frieza mui grande"; orvalho: "vapor, que se desfaz em miúdas gotas, e cai do ar à noite ou na madrugada"; sereno: "o sereno da noite; i. é, o ar vaporoso, orvalhoso della"; neblina: "nevoa espessa, nevoeiro, cerração, que talvez se acompanha de muita humidade"; cerração: "escuridão de nevoeiro, ou nuvens grossas d'inverno".

As definições apresentadas pelos lexicógrafos evidenciam, como sema comum, o traço semântico umidade, o que pode justificar o uso da unidade lexical neve para denominar referentes que abrigam essa característica.

É sabido que a migração interna no Brasil produziu uma alteração profunda no tabuleiro linguístico regional. O ALMESEMT, por exemplo, demonstrou que, ao invés de uma marca linguística individual, na Mesorregião Sudeste de Mato Grosso há um conjunto de traços que caracterizam a região e, da mesma forma, perpetua a linguagem de outras regiões do Brasil. A variante neve, registrada no vocabulário dos falantes dessa região, representa, pois, a norma das localidades nas quais essa variante foi documentada, ou seja, como apresenta "la realización 'coletiva' del sistema, que contiene el sistema mismo y además, los elementos funcionalmente 'no-pertinentes' pero normales en el hablar de una comunidad"(ALVAR, 1958, p. 85). Do mesmo modo, representa a fala de outras comunidades que, como demonstra o Quadro I, se 
instalaram na região, no final do século $\mathrm{XX}$, atraídas pela terra fértil e barata.

Considerando o processo migratório operado na região e as mudanças e variações linguísticas observadas entre os informantes das duas gerações investigadas, nota-se que, por um lado, os informantes da segunda faixa etária do ALMESEMT preservam os traços linguísticos de seus antecedentes nordestinos, como evidenciam os dados mapeados na carta de $\mathrm{n}^{\circ} 13$, anteriormente apresentada. Por outro lado, os informantes da primeira faixa etária dão preferência para o uso de neblina/ cerração, fator que aponta para um provável desaparecimento da variante neve na acepção focalizada neste trabalho, em decorrência da influência da escola e dos avanços dos meios de comunicação que possibilitam a ampliação dos conhecimentos gerais da população.

\section{Considerações finais}

Esse artigo teve como propósito associar a expansão diatópica da unidade lexical neve com o movimento migratório ocorrido na Mesorregião Sudeste mato-grossense, no final do século XIX e início do século XX.

As variedades linguísticas registradas no Atlas Linguístico da Mesorregião Sudeste de Mato Grosso evidenciam a influência da fala de outras regiões do Brasil, como ficou constatado na comparação entre os dados mapeados nos atlas linguísticos consultados, para nomear o que molha a grama de manhã e a fumaça que cobre tudo de manhã, e os documentados pelos atlas linguísticos de Estados das regiões Nordeste, Sudeste, Sul e Centro-Oeste, consultados neste estudo.

As pesquisas geolinguísticas, à medida que registram diferentes designações para um referente, correspondentes às ocorrências atribuídas aos falantes/ouvintes de uma dada comunidade linguística numa determinada época, documentam a língua em uso e, consequentemente, mudanças em curso na língua. No caso do ALMESEMT, foi registrada uma realidade linguística influenciada pelos movimentos migratórios que se processaram 
nas diferentes fases do povoamento do Sudeste de Mato Grosso. Em um primeiro momento, nordestinos, goianos e mineiros e, em um segundo, os sulistas, sobretudo os gaúchos.

Em síntese, a análise do comportamento da variante neve apontou para a existência de uma correlação entre a fala de outras regiões do Brasil e a registrada pelo ALMESEMT, ratificando a influência da história social no uso da língua, em particular na norma lexical partilhada por uma comunidade linguística.

\section{Referências}

AGUILERA, Vanderci de Andrade. A Geolingüística no Brasil: caminhos e perspectivas. Ed. UEL Londrina, 1998.

Atlas lingüístico do Paraná. Curitiba: Imprensa Oficial do Paraná, 1994.

ALVAR, Miguel. Diferencias en el habla de hombre y mujeres. Revista do Livro, Rio de Janeiro, n. 121, p. 85, 1958.

ARAGÃO, Maria do Socorro S.; MENEZES, Cleusa P. B. Atlas lingüístico da Paraíba. Cartas léxicas e fonéticas. v. 1. Brasilia: CNPq/UFPB, 1984.

Atlas lingüístico da Paraíba. Análise das formas e estruturas lingüísticas encontradas. v. 2. Brasília: CNPq/ UFPB, 1984.

COMITÊ NACIONAL DO PROJETO ALiB. Atlas lingüístico do Brasil: questionário 2001. Londrina: UEL, 2001.

COSERIU, Eugênio. O Homem e sua linguagem. Rio de Janeiro: Presença; São Paulo: Universidade de São Paulo, 1982.

CUBA, Marigilda Antônio. Atlas Linguístico da Mesorregião Sudeste de Mato Grosso. Dissertação (Mestrado em Estudos de Linguagens) - Universidade Federal de Mato Grosso do Sul, Campo Grande, 2009. 
CUNHA, Antonio Geraldo da. Dicionário etimológico Nova Fronteira da Língua Portuguesa. Rio de Janeiro: Nova Fronteira, 1996.

FERREIRA, Aurelio Buarque de Holanda. Novo Aurélio século XXI: o dicionário da língua portuguesa. 3. ed. Rio de Janeiro: Nova Fronteira, 2000.

ISQUERDO, Aparecida Negri. Designações para estilingue em atlas lingüísticos brasileiros: perspectivas diatópica e sócio-histórica. In: TROTTER, David (Ed.) Actes du XXIV Congress International de Linguistique et de Philologie Romanes. Tome I. Tübingen: Max Niemeyer Verlag, 2007. p. 533-546.

MACHADO, José Pedro. Dicionário etimológico da Língua Portuguesa. Lisboa: Livros Horizonte, 1987. 5 v.

MORAES SILVA, Antonio de. Diccionario da lingua portugueza. Rio de Janeiro: Livraria Francisco Alves, 1922. (Edição FAC-SÍMILE da segunda edição (1813), edição commemorativa do primeiro centenário da Independência do Brasil).

OLIVEIRA, Dercir Pedro de (Org.). Atlas Lingüístico de Mato Grosso do Sul. Campo Grande: Editora UFMS, 2007.

RIBEIRO, José; ZÁGARI, Mário Roberto L.; PASSINI, José; GAIO, Antonio. Esboço de um Atlas Lingüístico de Minas Gerais - EALMG. Rio de Janeiro: Fundação Casa de Rui Barbosa/ Universidade Federal de Juiz de Fora, 1977. v. 1.

ROSSI, Nelson. Atlas prévio dos falares baianos. Rio de Janeiro: INL; MEC, 1963.

THUN, Harald. La géographie linguistique romane à la fin du XX siécle. In: VERLAG, Max Niemeyer (Org.). Actes du XXII ${ }^{\mathbf{e}}$ Congrès International de Linguistique et de Philologie Romanes: Vivacité et divercité de la variation linguistique. v. 3. Bruxelas: Université Libre de Bruxelles, 1998. 